\title{
As competências do bibliotecário de referência frente ao paradigma pós-custodial
}

\author{
Thiago Pinheiro Ramos de Oliveira \\ Universidade Federal do Ceará, Departamento de Ciência da Informação, Fortaleza, CE, Brasil \\ thiagobiblio.oliveira@hotmail.com \\ Maria de Fátima Oliveira Costa \\ Universidade Federal do Ceará, Departamento de Ciência da Informação, Fortaleza, CE, Brasil \\ fatima12oliveiracosta@gmail.com \\ Jefferson Veras Nunes \\ Universidade Federal do Ceará, Departamento de Ciência da Informação, Fortaleza, CE, Brasil \\ jefferson.veras@yahoo.com.br
}

DOI: https://doi.org/10.26512/rici.v13.n1.2020.24073

Recebido/Recibido/Received: 2019-04-14

Aceitado/Aceptado/Accepted: 2019-10-03

Resumo: Discute as competências do bibliotecário de referência frente ao paradigma pós-custodial com o objetivo de apontar atributos que potencializem o desenvolvimento de competências e aplicá-los aos bibliotecários que atuam no serviço de referência e informação ofertado em bibliotecas. Realiza breves considerações a respeito do fenômeno "informação", abordando o surgimento da Ciência da Informação e os paradigmas custodial e pós-custodial abordados por Malheiro e Ribeiro (2011). Exibe conceitos e características do serviço de referência e informação, levando em consideração a influência das ferramentas tecnológicas nas atividades desenvolvidas. Aponta a gestão de competência apresentada por Thomas Durand (2006) através do trinômio conhecimento, habilidade e atitude (CHA). Trata-se de um estudo teórico, baseado em pesquisa bibliográfica que utilizou autores como Hjorland e Capurro (2007), Zins (2007), Araújo (2014), Malheiro e Ribeiro (2011), Grogan (1995) e outros. Conclui que o bibliotecário necessita saber o que informar, como utilizar as ferramentas para informar e ter atitude para desempenhar com qualidade o serviço de referência.

Palavras-chave: serviço de referência. serviço de informação. competência profissional. bibliotecário de referência. ; paradigma pós-custodial.

\section{The skills of the reference library in front of the post-custodial paradigm}

Abstract: The article discusses the competences of the reference librarian front the post-custodial paradigm with the objective of pointing out attributes that enhance the development of competences and apply them to librarians who work in the reference and information service. It makes brief considerations about the phenomenon "information", addressing the emergence of Information Science and the custodial and post-custodial paradigms addressed by Malheiro and Ribeiro (2011). It shows concepts and characteristics of the service of reference and information, considering the influence of the technological tools in the developed activities. It points to competence management presented by Thomas Durand (2006) through the trinomial knowledge, skill and attitude (CHA). It is a theoretical study, based on bibliographic research that used authors such as Hjorland and Capurro (2007), Zins (2007), Araújo (2014), Malheiro and Ribeiro (2011), Grogan (1995) and others. It concludes that the librarian needs to know what to report, how to use the tools to inform and have attitude to carry out the reference process.

Keywords: reference service. information service. professional skills. reference librarian. post-custodial paradigm. 
Las competencias del bibliotecario de referencia frente al paradigma post-custodial

Resumen: Discute las competencias del bibliotecario de referencia frente al paradigma post-custodial con el objetivo de apuntar atributos que potencien el desarrollo de competencias y aplicarlos a los bibliotecarios que actúan en el servicio de referencia e información ofertado en bibliotecas. Se realiza breves consideraciones acerca del fenómeno "información", abordando el surgimiento de la Ciencia de la Información y los paradigmas custodiales y post-custodiales abordados por Malheiro y Ribeiro (2011). Muestra conceptos y características del servicio de referencia e información, teniendo en cuenta la influencia de las herramientas tecnológicas en las actividades desarrolladas. Se señala la gestión de competencia presentada por Thomas Durand (2006) a través del trinomio conocimiento, habilidad y actitud (CHA). Se trata de un estudio teórico, basado en la investigación bibliográfica que utilizó autores como Hjorland y Capurro (2007), Zins (2007), Araújo (2014), Malheiro y Ribeiro (2011), Grogan (1995) y otros. Concluye que el bibliotecario necesita saber qué informar, cómo utilizar las herramientas para informar y tener actitud para desempeñar con calidad el servicio de referencia.

Palabras clave: servicio de referencia. servicio de información. competencias profesionales. bibliotecario de referencia. paradigma post-custodial.

\section{Introdução}

Atender ao usuário em suas necessidades de informação é o principal objetivo da biblioteca, independentemente de sua modalidade. Destarte, todos os serviços oferecidos pelas bibliotecas são desenvolvidos com o intuito de possibilitar o acesso dos usuários à informação que eles necessitam para suprir lacunas informacionais, dentre os quais, encontrase o Serviço de Referência e Informação.

O Serviço de Referência e Informação nasceu da necessidade de um acolhimento do bibliotecário para com o usuário, com o objetivo de ajudá-lo a entender que o ambiente da biblioteca além de proporcionar conhecimento era composto por bibliotecários capazes de agir com cordialidade, proporcionando um diálogo saudável e confiável. Samuel Green em 1876 já defendia a ideia de que era necessário um bibliotecário que oferecesse assistência ao leitor. Este profissional, atualmente conhecido como bibliotecário de referência, precisa dispor de atributos que contribuam para atender o usuário de forma que ele seja inserido em um ambiente favorável à construção do conhecimento.

Pesquisas da área da Ciência da Informação abordam a temática "Serviço de Referência e Informação" buscando contribuir para refletir e propor melhorias a respeito das possibilidades de mediação no processo de atendimento ao usuário, visando à apropriação da informação. O usuário, influenciado pelos avanços tecnológicos, lida com novos formatos de documentos e novos contextos informacionais, sendo exposto a milhares de informações. Para atender a este tipo de usuário o bibliotecário necessita adquirir conhecimentos tácitos e explícitos, desenvolver habilidades e tomar atitudes para atuar neste contexto que é permeado pelo paradigma pós-custodial apresentado por Malheiro e Ribeiro (2011).

Face ao paradigma pós-custodial este artigo é norteado pela seguinte questão: Quais atributos contribuem para o desenvolvimento de competências necessárias ao bibliotecário no 
que tange a atuação do serviço de referência e informação? Visando obter respostas para esta pergunta elegeu-se como objetivo geral identificar atributos que potencializem 0 desenvolvimento de competências e aplicá-los aos bibliotecários que atuam no serviço de referência e informação.

Este estudo possui uma abordagem teórica baseada em uma pesquisa bibliográfica a respeito das temáticas: "serviço de referência e informação", "paradigmas custodial e póscustodial da Ciência da Informação" e "competências do bibliotecário de referência".

\section{Ciência da informação: paradigmas custodial e pós- custodial}

A informação, ao ser percebida como fenômeno social que influencia direta ou indiretamente nas escolhas dos indivíduos, tem sido objeto de estudo de diversas pesquisas e nos mais variados contextos. Este fenômeno tem crescido mediante os acontecimentos históricos, o desenvolvimento e uso de ferramentas tecnológicas, que potencializam a sua disponibilização à sociedade.

Alguns estudos apresentam diversos conceitos de informação. Nesse sentido, Hjorland e Capurro (2007, p. 161) afirmam que “[...] para Machlup, a informação é um fenômeno humano. Envolve indivíduos transmitindo e recebendo mensagens no contexto de suas ações possíveis”. Já nos estudos apresentados por Zins (2007, p. 12),“a informação é o produto final do processamento de dados. O conhecimento é o produto final do processamento da informação". Brookes (1980), por sua vez, entende a informação como uma pequena parte do conhecimento, cujo autor define como a estrutura de conceitos ligados por suas relações.

A necessidade de registrar as informações impulsionou a criação de diversos suportes. A informação registrada em um suporte é denominada de documento. Alguns teóricos defendem a ideia de que o documento está estritamente relacionado ao registro de informações em papel. "O teórico indiano Ranganathan, geralmente metafísico, adotou uma abordagem curiosa e posição pragmática sobre a definição de "documento", resistindo inclusive à inclusão de materiais audiovisuais como as comunicações de rádio e televisão". (Buckland, 1997, p. 5, tradução nossa). Divergindo desta concepção Otlet (1934, p. 2017 apud BUCKLAND, 1997, p. 3) salienta que "registros gráficos e escritos são representações de ideias ou de objetos, mas os objetos em si podem ser considerados "documentos" se você for informado pela observação deles". Para Suzanne Briet (1951, p. 7 apud BUCKLAND, 1997, p. 4, tradução nossa) "um documento é qualquer signo físico ou simbólico, preservado ou gravado, destinado a representar, reconstruir ou demonstrar um fenômeno físico ou conceitual".

Independente de suporte, a necessidade de organização da informação é algo notório, por isso foram desenvolvidos, ao longo do tempo, técnicas, metodologias e produtos que 
fossem utilizados para organizar os documentos. De acordo com o desenvolvimento das técnicas de organização de documentos foram estabelecidas as disciplinas de Biblioteconomia, Arquivologia e Museologia como área de conhecimento. A história dessas disciplinas é marcada inicialmente por uma perspectiva de custódia dos documentos. O suporte informacional era tratado como algo tão importante que deveria ser guardado de tal maneira que poucas pessoas tinham acesso a eles. Araújo $(2014$, p. 3) diz que "a consolidação disciplinar destas três áreas no século XIX são importantes, pois será no diálogo com (ou melhor, na oposição a) estas áreas, conformadas desta maneira, que se construiu a ideia de uma Ciência da Informação".

A Ciência da Informação se constitui como campo científico em 1960 com a proposta de estudar a informação com um olhar direcionado à disponibilização dos documentos e acesso à informação. Tendo em vista a evolução dos conceitos que marcam as características do fazer do profissional da informação, faz-se necessário, neste estudo, a apresentação dos paradigmas custodial e pós-custodial da Ciência da Informação.

Malheiro e Ribeiro (2011) em estudo sobre os paradigmas, serviços e mediações na Ciência da Informação, interligam o princípio da Ciência da Informação, Documentação,Biblioteconomia, Arquivologia e Museologia ao contexto do que eles conceituam como Paradigma custodial.

O paradigma custodial possui um caráter patrimonialista, historicista e tecnicista. Os profissionais que atuavam em bibliotecas, arquivos e museus na perspectiva do paradigma custodial carregava em suas práxis a supervalorização das técnicas de acondicionamento dos itens em consonância com a ideia de preservar o suporte objetivando apenas a guarda e custódia dos documentos.De acordo com Silva, Cavalcante e Nunes (2018, p. 101) o paradigma custodial refere-se "às práticas custodiais de origem milenares nas bibliotecas, arquivos e museus, em que o foco de suas atividades se encontrava na guarda e custódia dos acervos".

Este modelo de gestão e mediação de Sistemas de Informação apresenta como traços principais a sobrevalorização da guarda, conservação e restauro do suporte; a identificação com a preservação da cultura erudita e da memória oficial - a fonte legitimadora dos Estados-nação. (GOVEIA JÚNIOR, 2014, p. 160).

Os traços essenciais abordados denotam o contexto em que os arquivos, bibliotecas e museus se encontravam. Contexto marcado pela restrição das informações já que o objetivo principal era apenas a guarda do suporte com vistas à preservação da memória. Mas a intenção de preservar a memória numa perspectiva de guarda e não de acesso. Malheiro e Ribeiro (2011) relacionam traços essenciais do paradigma custodial, os quais seguem apresentados na figura 1. 
Figura 1 - Traços essenciais do Paradigma Custodial

Sobrevalorização da custódia ou guarda, conservação e restauro do suporte como função basilar da atividade profissional de arquivistas e bibliotecários.

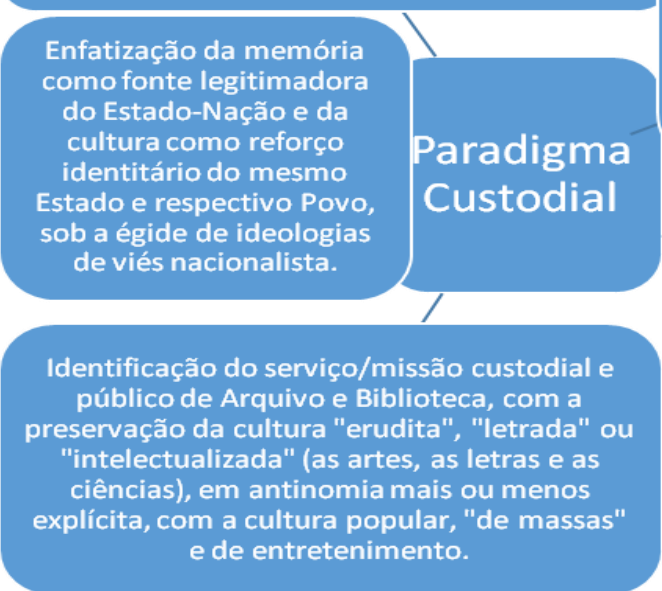

Importância crescente do acesso ao "conteúdo", através de instrumentos de pesquisa (guias, inventários, catálogos e índices) dos documentos e do aprofundamento dos modelos de classificação e indexação, derivados do importante legado tecnicista e normativo dos belgas Paul Otlet e Henri La Fontaine, com impacto na área da documentaçäo científica e técnica, possibilitando a multiplicação de Centros e Serviços de Documentação/Informação, menos vocacionadas para a custódia e mais para a disseminaçäo informacional.

Prevalência da divisäo e assunç̃o profissional Prevalência da divisão e assunção profissional
decorrente da criação e desenvolvimento dos decorrente da criação e desenvolvimento dos
serviços/instituições Arquivo e Biblioteca, indu tora de um arreigado e institivo espírito cooprporativo que fomenta a confusäo entre profissăo e ciência (persiste a ideia equivoca de que as profissöes de arquivista, de bibliotecário e de documentalista geram naturalmente, disciplinas cientificas autônomas como a Arquivistica, a Bibliotecologia/Biblioteconomia ou a Documentação).

Fonte: Malheiro e Ribeiro (2011, p. 34-35).

No que tange a biblioteca, observa-se a presença desta perspectiva custodial refletida nos serviços e produtos oferecidos até o início do século XX. As técnicas de organização e representação da informação eram baseadas em padrões tradicionalistas que visavam a custódia dos documentos. Os bibliotecários agiam como verdadeiros guardiões de documentos, sendo a regra o cuidado e a guarda.

Nos primeiros relatos sobre o que deveria ser a Ciência da informação havia a crítica ao bibliófilo, ao bibliotecário erudito, ao historiador atuante nos arquivos - a crítica de que tais profissionais focavam-se no "conteúdo" das obras, na instituição custodiadora, em vez de se preocuparem em promover a disseminação, a circulação e o efetivo uso das obras custodiadas. (ARAÚJO, 2014, p. 3).

No entanto, com o desenvolvimento de novas técnicas de classificação e catalogação, influenciadas por Otlet e La Fontaine, inicia-se o processo de transição emergente para um novo paradigma que iria suplantar o modelo de custódia dos documentos e passaria a priorizar o acesso à informação. Esta nova perspectiva solicita do profissional da informação novas competências que possibilite desempenhar funções adequadas objetivando a disponibilização das informações e o acesso aos usuários.

Anterior à Segunda Guerra Mundial e a explosão informacional, os serviços oferecidos pelas bibliotecas arquivos e museus se resumiam a custódia para a guarda e proteção dos documentos. Esta visão foi sendo modificada em contraposição ao tradicionalismo inerente à guarda patrimonialista dos dispositivos, gerando novos serviços, produtos e fluxos 
informacionais. Esta nova visão ocasionou o que Malheiro e Ribeiro (2011) chamam de paradigma pós-custodial.

O paradigma pós-custodial, influenciado pelos ideais iluministas, reflete nas práticas e nos fluxos informacionais, pois nesta perspectiva o objetivo das unidades de informação se concretiza no acesso à informação pelos usuários, a fim de suprir suas necessidades. 0 paradigma pós-custodial carrega em seus traços essenciais citados por Malheiro e Ribeiro (2011) o incentivo à socialização do conhecimento, dando à informação características de dinamicidade, de movimento em oposição ao modelo custodial que tratava a informação como algo estático, preso em um suporte que deveria ser preservado pelo seu valor patrimonial. A figura 2 apresenta os traços essenciais do paradigma pós-custodial.

Figura 2 - Traços Essenciais do Paradigma Pós-custodial

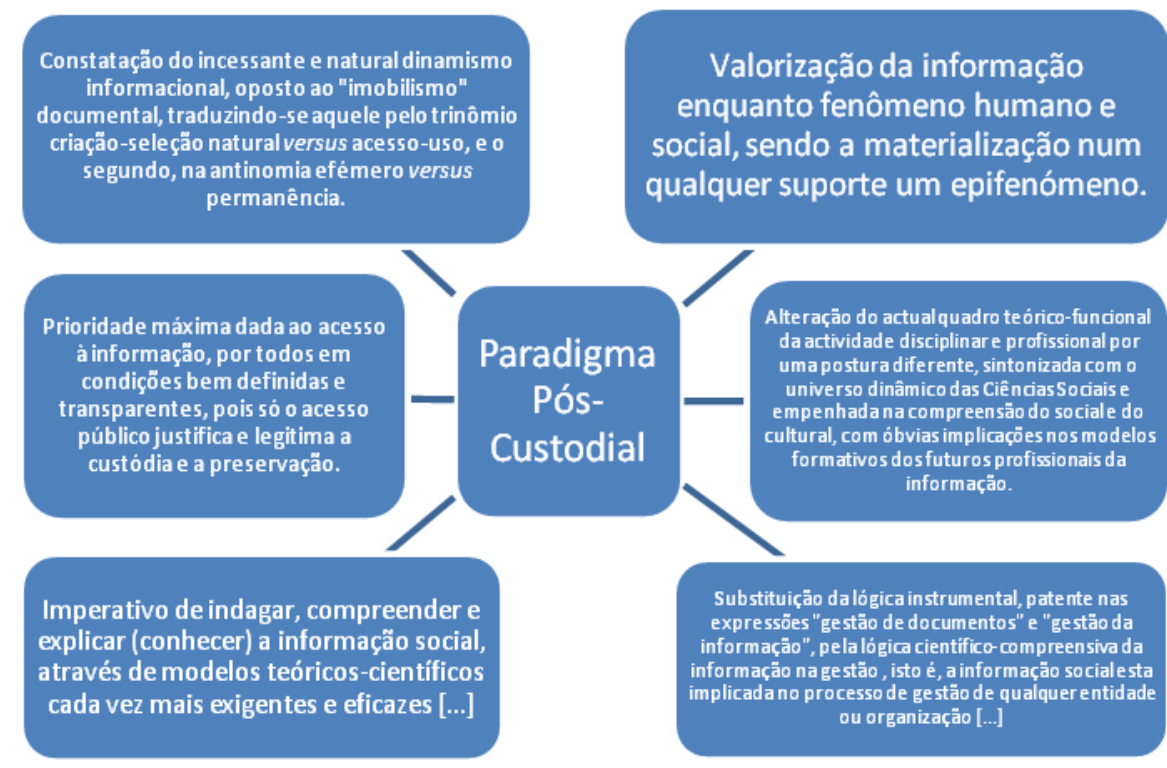

Fonte: Malheiro e Ribeiro (2011, p. 59-60).

Com a mudança de paradigma, as instituições informacionais e os profissionais da informação passaram desenvolver novas competências para atender a esta demanda. A partir desta perspectiva passou-se a estudar temáticas relacionadas ao estudo de usuários, mediação da informação,representação e recuperação tendo em vista a intenção do acesso do usuário.

No contexto de atender a necessidade de informação do usuário, disponibilizando-as e tornando-as acessíveis cabe tecer considerações a respeito do Serviço de Referência e Informação. Conforme Ana, Siqueira e Gerlin (2011, p. 22):

O serviço de referência possui suas origens a partir das discussões do bibliotecário Samuel Green, que formulou uma proposta para assistir aos 
leitores das bibliotecas. Grogan (1995) historia essa trajetória inicial enfatizando que tal serviço foi gerado a partir da necessidade de se adentrar o leitor com o acervo, motivando uma aproximação mais profunda do usuário com o conjunto de informações armazenadas.

Considerado como atividade fim de unidades de informação, em especial a biblioteca, o serviço de referência possui um caráter totalmente pós-custodial, já que sua finalidade está em atender e capacitar os usuários com o objetivo de proporcionar a liberdade de pesquisa, tornando-os autônomos em suas buscas.De acordo com Brandão e Borges (2016, p. 14) "no paradigma pós-custodial, o usuário é motivado a que ele mesmo defina a estratégia de busca e a conduza para atingir suas próprias necessidades informacionais".

Neste contexto percebe-se que o bibliotecário de referência deve adotar uma postura de significação social da informação, levando em consideração a realidade social, cultural, política e religiosa que formam o repertório dos usuários a fim de atuar como mediador da informação e como potencializador de competências em informação.

\section{Serviço de referência e informação}

Em 1876 o bibliotecário do Congresso, Spofford (1876 apud GENZ, 1998, tradução nossa) disponibilizou obras de referência como estratégia de economizar o tempo do bibliotecário e o do usuário no momento de suas pesquisas. Neste mesmo ano Green (1876 apud GENZ, 1998) defendeu a ideia de o bibliotecário assistir o leitor em suas necessidades de informação.

Green (1876 apud GENZ, 1998) percebia a relação entre bibliotecário e o usuário como a relação do lojista e cliente. Deste modo, o bibliotecário não deveria permitir que o usuário não obtivesse respostas às suas indagações, da mesma forma que o cliente não deveria sair de uma loja sem realizar uma compra. Entretanto, na visão do autor, o bibliotecário não deveria tornar os usuários dependentes de seus auxílios, e sim capacitá-los para desenvolver suas pesquisas com autonomia. "Dê-lhes o máximo de assistência que precisarem, mas ao mesmo tempo, tente ensiná-los a confiar em si mesmos e torna-se independentes". (GREEN, 1876, p. 80 apud GENZ, 1998, p. 506, tradução nossa).

A assistência exclusiva que o bibliotecário oferta ao usuário foi denominada como Serviço de Referência. Segundo Accart $(2012$, p. 7) "Os serviços de referência surgem no final do século XIX nas bibliotecas públicas norte-americanas com o nome de reference services". Grogan (1995, p. 2) afirma que "o serviço de referência é a assistência pessoal prestada pelo bibliotecário aos leitores em busca de informações".Souza e Farias (2011) expressam que o serviço de referência é a oferta de serviços com o objetivo de apoio ao usuário para o uso e exploração dos recursos de informação que existem na biblioteca. 
Ao longo dos anos pesquisadores propuseram modelos de processo de referência. 0 modelo de referência tradicional compreende o atendimento presencial em um ponto específico, conhecido como balcão de referência. Neste balcão o bibliotecário responde às questões independentemente do nível de complexidade por intermédio de diálogo.

Na tentativa de diminuir a demanda para o bibliotecário foi proposto o modelo de serviço de referência em camadas, no qual são implantados dois ou mais pontos de atendimento na biblioteca, sendo ocupados por assistentes treinados para responder a questões mais simples, deixando apenas as questões complexas para os bibliotecários.

De acordo com Grogan (1995) as solicitações expostas pelos usuários, conhecidas como questões de referência, podem ser classificadas como simples ou complexas. A questão simples aborda fatos, acontecimentos e definições podendo ser respondida a partir de pesquisa bibliográfica no interior da biblioteca. A questão complexa apresenta dificuldade de recuperação podendo ser respondida através de recursos variados encontrados dentro ou fora da instituição.Ao abordar o serviço de referência Grogan (1995) descreve passo a passo do processo de referência, conforme apresentado no quadro 1.

Quadro 1 - Processo de referência de Grogan

\begin{tabular}{|l|l|}
\hline \multicolumn{2}{|c|}{ PROCESSO DE REFERÊNCIA - GROGAN } \\
\hline Problema & $\begin{array}{l}\text { O processo geralmente se inicia com um } \\
\text { problema que atrai a atenção de um usuário } \\
\text { potencial da biblioteca. }\end{array}$ \\
\hline Necessidade de informação & $\begin{array}{l}\text { Inquietação do usuário a respeito de algo que } \\
\text { algumas vezes não sabe identificar. }\end{array}$ \\
\hline Questão inicial & $\begin{array}{l}\text { Perguntas elaboradas pelo usuário em busca de } \\
\text { informações que o levem a resposta. }\end{array}$ \\
\hline Questão negociada & $\begin{array}{l}\text { Ocorre a partir do momento em que o } \\
\text { bibliotecário de referência recebe as questões } \\
\text { realizadas pelo usuário, verificando o interesse } \\
\text { pelas outras fases. }\end{array}$ \\
\hline Estratégias de busca & $\begin{array}{l}\text { Primeiramente o bibliotecário analisa } \\
\text { minuciosamente o tema em questão e } \\
\text { posteriormente são verificadas quais secções e em } \\
\text { que ordem serão consultadas e qual o melhor } \\
\text { caminho para adquirir a suposta informação, } \\
\text { realizando a seleção da categoria da fonte, da fonte } \\
\text { específica e dos pontos de acessos específicos. }\end{array}$ \\
\hline Processo de busca & $\begin{array}{l}\text { O bibliotecário realiza a busca no acervo de } \\
\text { forma flexível, possibilitando a mudança na } \\
\text { busca, caso haja necessidade. }\end{array}$ \\
\hline Solução & $\begin{array}{l}\text { Resultado da busca. } \\
\text { usuário, resolvendo o seu problema } \\
\text { informacional. }\end{array}$ \\
\hline
\end{tabular}

Fonte: Grogan (1995, p. 51-54). 
A partir da apresentação deste processo, percebe-se o protagonismo do bibliotecário de referência em todo o percurso na busca pela solução dos problemas e necessidades informacionais dos usuários. Souza e Farias (2011) conceitua o profissional responsável pelo serviço de referência de uma biblioteca como aquele especializado em assistir ao usuário na utilização das fontes de pesquisa.

Com desenvolvimento das tecnologias e seu uso no serviço de referência e informação foram sendo criados novos modelos de processo de referência. O modelo call center, foi proposto a fim de diminuir custos pelas transações de referência. Neste modelo a equipe atua em estações com acesso a bancos de dados e lista de perguntas e respostas frequentes. Outro modelo de processo de referência proposto foi o "Commons da Informação", neste modelo o atendimento é realizado exclusivamente em ambiente online, por meio de serviços oferecidos em uma única interface.

O uso das tecnologias, em especial o acesso à internet tem contribuído significativamente para a eficácia do serviço de referência nos ambientes virtuais. Moreno (2005, p. 36) explica que:

A disponibilização do serviço de referência digital, através de uma página da Internet, tem gerado uma nova demanda para as bibliotecas, que a partir de então, independente da localização geográfica de seus usuários, permite que o acessem, fornecendo facilidade de acesso à informação de forma rápida, com baixo custo, abrindo um novo horizonte para a pesquisa: busca e obtenção de informações de qualquer tipo.

Alves e Vidotti (2006)utilizam o termo serviço de referência e informação digital, classificando-o como assíncronos exemplificados pelo e-mail; e síncronos exemplificados pelos chats e vídeo conferência. Márdero Arellano (2001) apresenta que a criação de novos softwares propulsionou a mudança de serviços acessados remotamente para 0 desenvolvimento de redes colaborativas de bibliotecas, podendo estender o conceito para serviços virtuais.

O serviço de referência virtual surgiu na década de 1980 quando bibliotecas americanas disponibilizaram seus catálogos na rede para serem consultados, facilitando a localização do documento e permitindo o usuário realizar perguntas por meio de links. Conforme Márdero Arellano (2001, p. 8), este serviço, conhecido como Ask a Librarian(Pergunte a um bibliotecário), é criado pelo departamento de referência e "disponibilizado na home page da biblioteca, aumentando consideravelmente o número de consultas". Accart (2012, p. 181) apresenta que:

A definição proposta para o serviço de referência virtual é a seguinte: oferece um ponto de acesso único em linha que o usuário pode identificar imediatamente, ao qual ele apresenta uma solicitação, entregue aos 
cuidados de profissionais qualificados, solicitação esta que enseja uma resposta rápida, pertinente e de qualidade.

O avanço da tecnologia e as facilidades de acesso aos aparatos tecnológicos potencializou o uso dessas ferramentas para toda a sociedade. Isto ocasionou que as pessoas tivessem acesso mais célere a informação. Portanto, o bibliotecário se depara com usuários habilidosos no uso das tecnologias, sendo não só receptores, mas também produtores de informação e conhecimento através das wikis, dos blogues, entre outras mídias sociais. Para tanto, Agosto et al. (2011) propõem um modelo de processo de referência que abrangesse esse novo perfil de usuário da informação. Na figura 3 observamos que neste modelo os recursos informacionais: variam em formatos com conteúdo criados tanto pelos bibliotecários como pelos usuários, os bibliotecários podem se comunicar com os usuários utilizando várias formas de comunicação por meio das ferramentas tecnológicas e agem como instrutores ao filtrar e selecionar referências evitando a sobrecarga sob o usuário.

Figura 3 -Um modelo do processo de referência

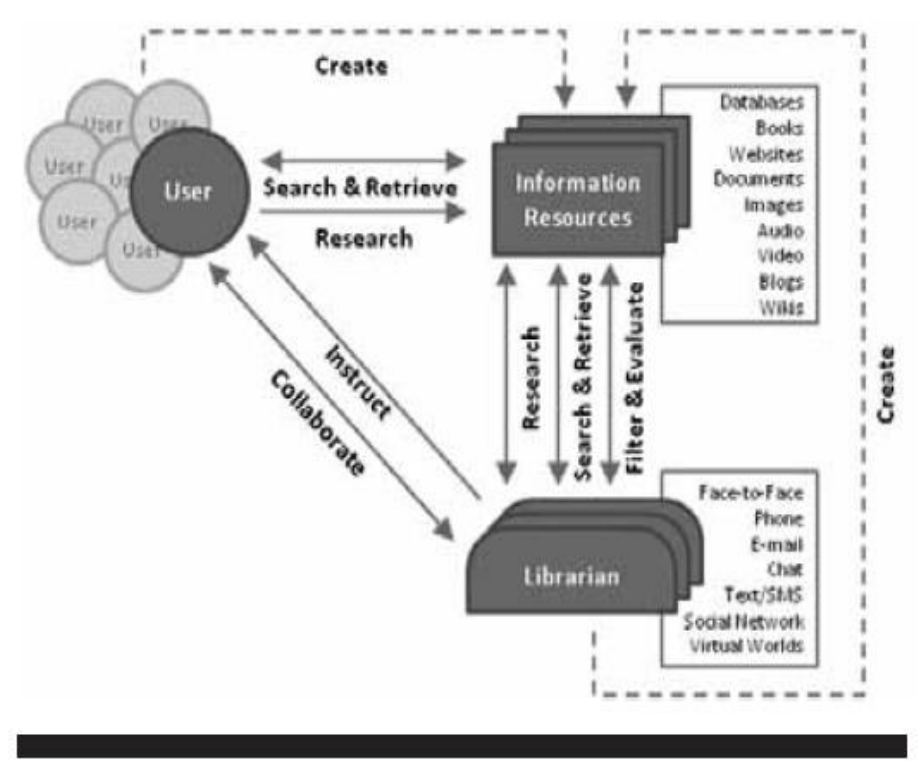

Fonte: Agosto et al. (2010, p. 241).

O serviço de referência virtual é uma realidade das bibliotecas e para que o bibliotecário atue satisfatoriamente como mediador neste processo de busca, torna-se necessário que desenvolva competências que possibilitem o uso de ferramentas, sejam elas tecnológicas ou não, que favoreçam a aproximação do usuário com as informações. 


\section{Competências do bibliotecário de referência no contexto do paradigma pós-custodial}

Ao perceber o cenário pós-custodial vivenciado pelas bibliotecas, faz-se necessário refletir a respeito das competências desenvolvidas pelos bibliotecários de referência, levando em consideração o modelo conceitual de gestão de competência especificado por Thomas Durand (2006).

A gestão de competências é a forma de alocar o pessoal baseado nas competências de cada colaborador, visando o sucesso da organização. Rossi, Costa e Pinto (2014) expõem que Durand (2006) apresenta que a competência se constitui pela composição do trinômio conhecimento, habilidade e atitude (CHA). O "conhecimento" consiste no "saber que?" ou "saber o que?". É entendido como informações estruturadas acomodadas que permitem a uma organização manter o funcionamento de suas atividades. "Habilidade"consiste no "saber como", nas técnicas utilizadas para alcançar os objetivos. E, por fim, a "atitude", nela está envolvida a ação, o comportamento, o "saber ser". Para Durand (2016) o profissional competente é capaz de utilizar o seu conhecimento para resolver seus problemas. Le Boterf (2003, p. 48) salienta que "o profissional não é aquele que possui conhecimentos ou habilidades, mas aquele que sabe mobilizá-los em um contexto profissional".

De acordo com Perrenoud (1997, p. 22) "construir uma competência significa aprender a identificar e a encontrar os conhecimentos pertinentes". Em conformidade com Durand (2006), Dutra (2001, 2004) e Fleury (2002) abordam que as competências humanas podem ser compreendidas como um conjunto de conhecimentos (saber), habilidades (saber fazer) e atitudes (saber ser). Zarifiam (2001), também destaca a competência definindo-a como a capacidade do indivíduo de ser proativo, de ir além do que está prescrito, de entender e dominar novos contextos com os quais se encontra no trabalho, de assumir responsabilidade sobre eles, e adquirir reconhecimento por isso. Fleury $(2002$, p. 55) propõe que competência é "saber agir responsável e reconhecido que implica saber mobilizar, integrar, transferir conhecimentos, recursos, habilidades, que agreguem valor econômico à organização e valor social ao indivíduo".

Inserido no paradigma pós-custodial, o bibliotecário que não mais é caracterizado como guardião dos suportes informacionais e sim como mediador da informação, em seu ambiente de trabalho, lida diretamente com o atendimento ao usuário a fim de auxiliá-lo a suprir a necessidade informacional. Neste contexto, tornar a informação acessível depende também do desenvolvimento de competências profissionais que contribuirão para o planejamento de estratégias que facilitarão o fluxo de informações. Utilizando-se dessas competências, o bibliotecário poderá de forma organizada administrar as demandas que 
ocorrerem e até mesmo antecipá-las. Para Le Boterf (2003) "o saber agir não consiste somente em saber tratar um incidente, mas, igualmente, em saber antecipá-lo".

Conhecimento, habilidade e atitude são atributos necessários para o bibliotecário de referência. Para informar é necessário saber o que informar. Por isso este profissional precisa estar constantemente atualizado e capacitado dentro do seu campo de atuação para que os objetivos dos serviços oferecidos pela biblioteca possam fazer sentido para o usuário.Ser um profissional de referência competente "requer experiência adquirida no exercício de uma profissão: formação sólida, cultura geral, conhecimento da área de atuação, domínio dos métodos e instrumentos, uma disposição especial para enfrentar qualquer tarefa". (ACCART, 2012, p. 79).

A figura 4 destaca competências pertinentes para o desempenho do processo de referência e assistência pessoal na perspectiva de Rossi, Costa e Pinto (2014, p. 8).

Figura 4: Competências para prestação do serviço: processo de referência/ assistência informacional.

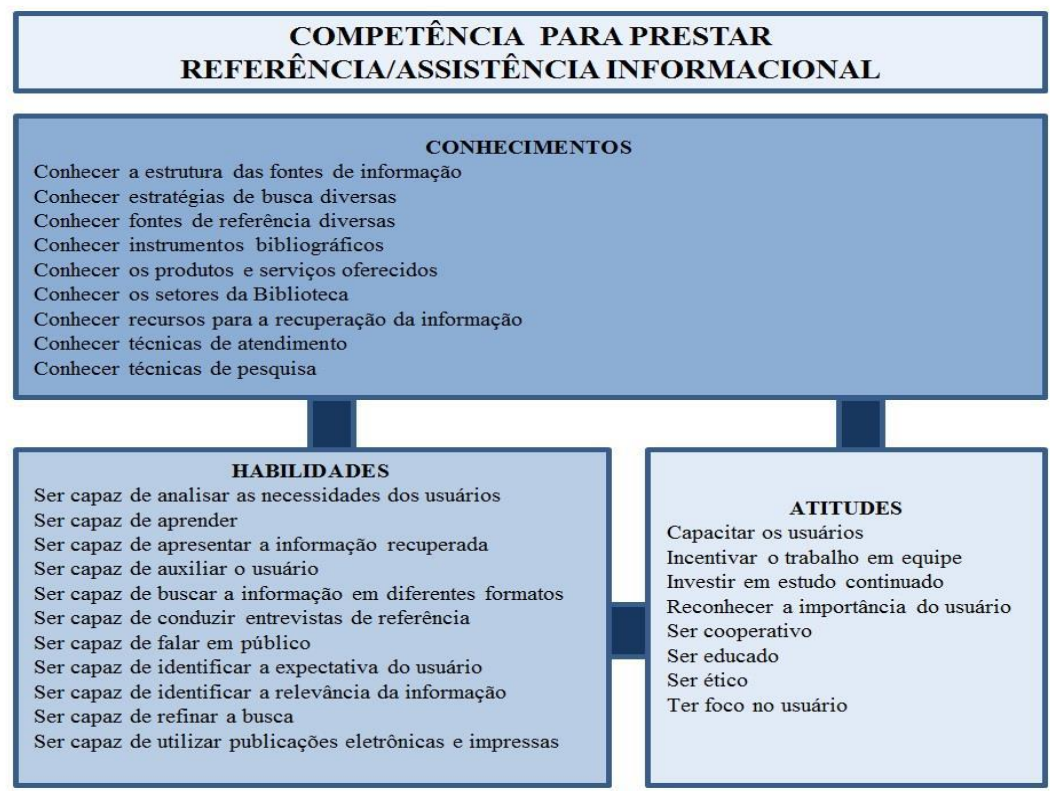

Fonte: Rossi, Costa e Pinto (2014, p. 8).

O conhecimento pode ser explícito ou tácito. O conhecimento explícito é aquele desenvolvido por meio da linguagem formal, enquanto o tácito ocorre através das experiências de vida. De acordo com Fleury (2002, p. 139) é possível fazer a distinção entre os dois tipos de conhecimento: "O conhecimento explícito, ou codificado, refere-se ao conhecimento transmissível em linguagem formal, sistemática, enquanto o conhecimento tácito possui uma qualidade pessoal, tornando-se mais difícil de ser formalizado e comunicado". 
É imprescindível desenvolver conhecimento para atuar na assistência ao usuário. Em termos de conhecimento explícito, cabe ressaltar a graduação para formação bibliotecária. 0 Ministério do Trabalho (2018, online)classifica o bibliotecário como profissional da informação capacitado para atuar de diversas maneiras nas unidades informacionais. 0 bibliotecário é o profissional bacharel em Biblioteconomia, ou Biblioteconomia e Documentação.A estrutura curricular dos cursos de Biblioteconomia é construída observando a necessidade do universo biblioteconômico. O serviço de referência e informação está inserido nos currículos das universidades, para que o estudante de biblioteconomia ao se formar seja capacitado para atuar no mercado de trabalho, considerando as questões de atendimento e capacitação do usuário. Após a graduação, o bibliotecário pode continuar adquirindo conhecimento nos Programas de Pós-Graduação em Ciência da Informação, área do conhecimento que abarca grandes contribuições para a biblioteconomia. Os cursos de capacitação oferecidos por Órgãos Públicos e Privados, também contribuem para dar subsídios necessários para que o bibliotecário construa conhecimentos que contribuirão para o desempenho de sua função. No que tange ao serviço de referência e informação conhecer o processo e as características de seu fluxo, possibilitará a comunicação entre usuário e bibliotecário facilitando a acomodação da informação.Cabe ressaltar também que o conhecimento advindo das experiências de vida do bibliotecário contribui para a sua qualificação. Cada usuário possui características e necessidades singulares que se percebido pelo bibliotecário facilitará o processo de referência. Todos os itens citados na categoria "conhecimento" na figura 3 podem ser desenvolvidos por meio dos conhecimentos tácitos e explícitos.

A segunda categoria do trinômio de Durand (2006) está representada pelas "habilidades". Semelhante o conhecimento, as habilidades podem ser desenvolvidas por meio de estruturas formais como também das vivências dos bibliotecários. Dewey (1883, p. 285 apud GENZ, 1998, p. 509, tradução nossa) delineou qualificações práticas para o bibliotecário de referência:

\footnotetext{
"Eles devem ter um conhecimento completo dos materiais da biblioteca, capacidade de discriminar as fontes de informação, habilidade em ajustar as fontes às necessidades do leitor e a capacidade de educar o leitor a utilizar o livro de referência de forma inteligente."
}

O pensamento de Dewey corrobora com as habilidades apresentadas como importantes no processo de referência,conforme apresentado na figura 4, pois elas são focadas na capacidade do bibliotecário de saber buscar a informação e disponibilizá-la por meio dos recursos informacionais para o usuário. Toda ação realizada pelo bibliotecário de referência precisa levar em consideração esses dois aspectos: aprender a buscar e saber 
instruir para comunicar. O bibliotecário de referência deve estar preparado para auxiliar o usuário neste contexto em que as informações circulam com rapidez e em grande quantidade.O bibliotecário precisa estar capacitado para atender a este usuário, agora não mais apenas auxiliando na busca da informação, mas identificando a segurança e fidedignidade das informações recuperadas.

No que se refere à necessidade de atualização e capacitação dos profissionais as habilidades no uso das ferramentas tecnológicas é tema recorrente nas pesquisas da área da Ciência da Informação, já que o uso das Tecnologias da Informação e Comunicação tem permeado os serviços das bibliotecas e potencializado a capacidade de acesso às informações. O serviço de referencial virtual é uma realidade em todos os ambientes informacionais.

\footnotetext{
Eles identificaram uma série de mudanças nos serviços de referência, incluindo um aumento na variedade de recursos eletrônicos disponíveis, ênfase nos serviços mediados, um aumento na variedade de serviços online disponíveis, um aumento na web como a plataforma padrão para recursos e serviços, uma diminuição no número e aumento na complexidade das questões e um aumento nas habilidades dos usuários no uso do computador. (AGOSTO et al., 2011. p. 236, tradução nossa).
}

O uso das ferramentas tecnológicas multiplica a capacidade de alcance dos acessos que de forma física se limita ao espaço. O bibliotecário deve ser capaz de utilizar o computador e a internet no processo de busca e mediação da informação. Saber acessar as bases e bancos de dados que atendem ao seu público alvo, utilizar os mecanismos e estratégias de buscas, comunicar-se de forma síncrona e assíncrona são habilidades que contribuem para o funcionamento dos serviços. No quesito capacitação do usuário as tecnologias têm contribuído com a oferta de cursos através dos ambientes virtuais de aprendizagem. Nestes ambientes os bibliotecários que possuem habilidades tecnológicas podem oferecer capacitação com atendimentos aos usuários sem a necessidade de estabelecer horário nem presença física.

Para além das habilidades é necessário que o bibliotecário de referência possua o que consta no terceiro item do trinômio do Durand (2006): atitude.Esta dimensão da competência é solidificada pelo comportamento e personalidade. Desta forma, será pertinente apresentar características que podem contribuir para que o bibliotecário de referência tome atitudes favoráveis ao desempenho de suas atividades.

Atender e instruir são ações que exigem do bibliotecário características altruístas diante do processo de referência. Para Genz (1998), graciosidade e cultivo são os principais critérios para oferecer assistência ao usuário. Essas características proporcionam um ambiente acolhedor, o qual as pessoas gostariam de frequentar. Genz (1998) apresenta dez principais traços de caráter, a saber: inteligência, precisão, julgamento, conhecimento profissional, 
confiabilidade, cortesia, desenvoltura, tato, atenção e interesse pelo trabalho. Conforme Moreno (2005), para que o bibliotecário de referência tenha êxito em sua assistência, deve se mostrar interessado e disposto a prestar qualquer serviço, criando um ambiente amistoso no qual o usuário se sinta à vontade.

Diante da conjuntura atual, cabe acrescentar a empatia a estes atributos. É de suma importância que o profissional que lida diretamente com o usuário seja empático, acolhedor, atencioso e ter sempre interesse em solucionar o problema, ou dar respostas que tenham significado para os usuários. Conforme Hutchins (1983, p. 18 apud MORENO, 2005, p. 27):

O relacionamento pessoal estabelecido entre o leitor e o bibliotecário é fundamental. A primeira qualidade de um bom bibliotecário de referência diz respeito a sua acessibilidade: ele deve não só estar num ponto de fácil acesso físico ao leitor, como deve ser muito acessível intelectual e espiritualmente.

A proatividade promove o sucesso no quesito acessibilidade. O bibliotecário que não se "esconde" por trás de um balcão, mas circula na biblioteca com o objetivo de estar disponível para assistir o usuário em suas necessidades de informação promove um ambiente de acolhimento e motiva os usuários a procurá-lo em outras situações.Para Genz (1998, p. 8, tradução nossa) "[...] há a sensação de que o bibliotecário é um guia para o que a biblioteca contém ou um intérprete de como ela funciona. O bibliotecário se senta e espera que o leitor busque orientação e instrução, em vez de adotar uma postura proativa".

O paradigma pós-custodial remete o bibliotecário a um momento profissional de transposição da importância das coisas para o ser humano. Estar atento e tornar as informações acessíveis são ações inseridas em atitudes, que necessitam que o bibliotecário possua um repertório intelectual baseado em seus conhecimentos e habilidades para utilização das ferramentas que forem necessárias para auxiliar no suprimento das necessidades de informação dos usuários.

\section{Considerações finais}

Partindo destes pressupostos, infere-se que no surgimento da Ciência da Informação a custódia de documentos apenas pela guarda do suporte com vistas patrimonialistas era orientada nos serviços das unidades informacionais. Entretanto, a ruptura deste paradigma se deu com ações baseadas no acesso à informação, as quais suplantaram o surgimento do paradigma pós-custodial.

Observou-se a importância do serviço de referência e informação nas unidades informacionais inserido no contexto pós-custodial, pois através do processo de referência o 
bibliotecário atua como mediador facilitando o acesso do usuário às informações. Este processo possibilita os usuários a se apropriar das informações e consequentemente suprir suas necessidades de informação.

Permitir o acesso é a principal característica do serviço de referência, mas para possibilitá-lo é necessário que o atendimento ao usuário seja realizado por bibliotecários competentes. De acordo com o estudo apresentado, o profissional competente é aquele que possui conhecimento, habilidades e atitudes para desempenhar as suas funções. Não basta apenas saber o que fazer, mas saber como fazer e querer realizar. Esses atributos são importantes ao bibliotecário, e expressados por qualificações adquiridas ao longo da vida através de conhecimentos tácitos e explícitos.

A qualificação no que tange ao uso de ferramentas tecnológicas é indispensável para que os bibliotecários superem as limitações físicas da assistência ao usuário e apresentem as diversas possibilidades de busca da informação por meio das fontes de informações registradas em variados suportes e diferentes formatos.

O bibliotecário de referência por ser um profissional que trabalha mediando informações diretamente com o público, seja de forma presencial ou virtual, necessita manter uma postura baseada no acolhimento e na empatia com o outro, enxergando como missão contribuir para o processo de apropriação da informação dos usuários.

Este estudo é relevante para reflexão dos profissionais e pesquisadores da área da Ciência da Informação sobre os paradigmas existentes no contexto epistemológico da área e de que forma isso influencia no serviço de referência e informação. Cabe refletir também sobre a importância de o bibliotecário buscar de maneira permanente sua capacitação, principalmente quanto às ferramentas tecnológicas, já que a sociedade está inserida em um contexto em que as tecnologias são utilizadas em todas as áreas de conhecimento. 0 bibliotecário de referência precisa permanentemente, ampliar o conhecimento, aprimorar suas habilidades e ter atitude para dispensar um atendimento eficaz aos seus usuários.

\section{Referências}

ACCART, Jean-Philippe. Serviço de referência: do presencial ao virtual. Brasília: Briquet de Lemos, 2012.

AGRASSO NETO, M.; ABREU, A. F. de. Conhecimento Científico: subsídios para gestão de serviços de referência e informação. Florianópolis: Editora da UFSC, 2009.

AGOSTO, D. E. L et al. A model of the reference and information services process: an educators perspective. Reference and User Services Quartely, v. 50, n. 3, p. 235-244, 2011. Disponível em: 
$<$ https://www.researchgate.net/publication/288407236_A_Model_of_the_Reference_and_Inf ormation_Service_Process_An_Educators'_Perspective>. Acesso em: 4 mar. 2019.

ALVES, A. P. M.; VIDOTTI, S. A. B. G. O serviço e referência e informação digital. Biblionline, João Pessoa, v. 2, n. 2, 2006. Disponível em:<http://periodicos.ufpb.br/ojs2/index.php/biblio/article/view/611/448>. Acesso em 25 jun. 2018.

ARAÚJO, C. A. Á. Fundamentos da ciência da informação: correntes teóricas e o conceito de informação. Perspectivas em Gestão \& Conhecimento, João Pessoa, v. 4, n. 1, p. 57-79, jan./jun. 2014.

BRANDÃO, G. S.; BORGES, J. Mediação da informação arquivística: o papel do arquivista póscustodial. Revista Analisando em Ciência da Informação, v. 4, n. especial, p. 118-136, 2016. Disponível em: <http://www.brapci.inf.br/v/a/28513>. Acesso em: 25 Jun. 2018.

BRASIL. Ministério do Trabalho e Emprego. Classificação Brasileira de Ocupações. Disponível em: <http://www.mtecbo.gov.br/cbosite/pages/pesquisas/BuscaPorTitulo.jsf>. Acesso em: 25 jun. 2018.

BROOKES, Bertram C. The foundations of information science. Journal of information science, v. 2, p. 125-133, 1980.10 Disponível <http://journals.sagepub.com/doi/10.1177/016555158000200302 >. Acesso em: 25 jun. 2018.

BUCKLAND, M. K. What is a "document"? Journal of the American Society for information science, Medford, v. 48, n. 9, p. 804-809, set. 1997.

CAPURRO, R; Hjorland, B. O conceito de informação. Perspectivas em Ciência da Informação, Belo Horizonte, v. 12, n. 1, p. 148-207, jan./abr. 2007. Disponível em: <http://portaldeperiodicos.eci.ufmg.br/index.php/pci/article/view/54/47>. Acesso em: 25 jun. 2018.

CELEDONIO DA SILVA, Ana Priscila; CAVALCANTE, Lidia Eugenia; VERAS NUNES, Jefferson. Informação e memória: aproximações teóricas e conceituais. Encontros Bibli: revista eletrônica de biblioteconomia e ciência da informação, Florianópolis, v. 23, n. 52, p. 95-106, maio 2018. ISSN 1518-2924. Disponível em: <https://periodicos.ufsc.br/index.php/eb/article/view/1518-2924.2017v23n52p95>. Acesso em: 25 jun. 2018.

DURAND, Thomas. L'alchimie de la competence. Revue Française de Gestion: theories mode d'emploi, França, n. 160, p. 261-292, 2006. Disponível em: <https://www.cairn.info/revuefrancaise-de gestion-2006-1-page-261.htm>. Acesso em: 4 mar. 2019.

DUTRA, J. S. Gestão por Competências: um modelo avançado para o gerenciamento de pessoas. São Paulo: Gente, 2001.

DUTRA, J. S. Competências: conceitos e instrumentos para gestão de pessoas na empresa moderna. São Paulo: Gente, 2004.

FLEURY, M. T. L. A gestão de competência e a estratégia organizacional, In: FLEURY, M. T. (Coord.). As Pessoas na Organização. São Paulo: Gente, 2002. 
GENZ, M. D. Working the reference desk. Library Trends, v. 46, n. 3, p. 505-525, Winter 1998.Disponível em: <https://core.ac.uk/download/pdf/4817503.pdf>. Acesso em: 04 mar. 2019.

GOUVEIA JUNIOR, Mário. O pensamento de baumaniano e os paradigmas de mediação da informação. Revista Digital de Biblioteconomia e Ciência da Informação, Campinas, SP, v. 13, n. 1, p. 156-169, jan. 2015. ISSN 1678-765X. Disponível em: <https://periodicos.sbu.unicamp.br/ojs/index.php/rdbci/article/view/1586>. Acesso em: 25 jun. 2018.

GROGAN, D. A prática do serviço de referência. Brasília: Briquet de Lemos, 1995.

LE BOTERF, Guy. Desenvolvendo a competência dos profissionais. Porto Alegre: Artmed, 2003.

MALHEIRO, A.; RIBEIRO, F. Paradigmas, serviços e mediações em Ciência da Informação. Recife: Néctar, 2011.

MÁRDERO ARELLANO, M. A. Serviços de referência virtual. Ciência da Informação., Brasília, v. 30, n. 2, p. 7-15, maio/ago. 2001. Disponível em: <http://www.scielo.br/pdf/ci/v30n2/6206>. Acesso em 15 set. 2018.

MORENO, Patrícia da Silva. Serviço de referência digital: uma análise apoiada em agentes de interface. 2005. 153f. Dissertação (Mestrado em Ciência da Informação) - Programa de PósGraduação em Ciências da Informação, Faculdade de Filosofia e Ciências, Universidade Estadual Paulista, Marília, 2005. Disponível em:<http://www.marilia.unesp.br/Home/PosGraduacao/CienciadaInformacao/Dissertacoes/moreno_ps_me_mar.pdf>. Acesso em 25 jun. 2018.

PERRENOUD, Philippe. Construir as competências desde a escola. Porto Alegre: Artmed, 1999.

ROSSI, Tatiana; COSTA, Marília Damiani; PINTO, Adilson Luiz. Competências requeridas aos bibliotecários na prestação de serviços de informação em Bibliotecas Universitárias. Revista ACB, v. 19, n. 1, p. 111-123, mar. 2014. Disponível em: <https://revista.acbsc.org.br/racb/article/view/941>. Acesso em: 25 jun. 2018.

SANTA ANNA, Jorge; SIQUEIRA, Poliana Silva; GERLIN, Meri Nadia Marques. Serviço de referência e tecnologia da informação: construindo múltiplas interfaces. Revista Brasileira de Biblioteconomia e Documentação, São Paulo, v. 11, n. 1, p. 20-40, jul. 2015. Disponível em: <https://rbbd.febab.org.br/rbbd/article/view/304>. Acesso em: 25 jun. 2018.

SOUZA, M. N. A. de; FARIAS, K. M. Bibliotecário de referência e a competência informacional. In.: CONGRESSO BRASILEIRO DE BIBLIOTECONOMIA, DOCUMENTAÇÃO E CIÊNCIA DA INFORMAÇÃO, $24 . \quad$ Disponível em: <http://febab.org.br/congressos/index.php/cbbd/xxiv/paper/view/530/674>. Acesso em 25 jun. 2018.

ZARIFIAN, P. Objetivo Competência: por uma nova lógica. São Paulo: Atlas, 2001.

ZINS, C. et al. Mapa do conhecimento da ciência da informação implicações para o futuro da área. Brazilian Journal of Information Science, v. 1, n. 1, p. 3-32, 2007. Disponível em: <http://www.brapci.inf.br/v/a/8751>. Acesso em: 25 Jun. 2018. 